\title{
PENGARUH GAYA KEPEMIMPINAN, MOTIVASI DAN DISIPLIN KERJA TERHADAP PRESTASI KERJA PEGAWAI PT. TAMAN WISATA CANDI BOROBUDUR, PRAMBANAN DAN RATU BOKO (PERSERO)
}

\author{
Efrat Tirta Wijaya \\ efrat.tirtawijaya@gmail.com \\ Universitas Ahmad Dahlan \\ Candra Vionela Merdiana \\ candra.vm@mgm.uad.ac.id \\ Universitas Ahmad Dahlan
}

\begin{abstract}
ABSTRAK
This study aimed to find out: (1) the influence of leadership style toward the work performance of employees in PT. TWC Borobudur, Prambanan \& Ratu Boko (Persero), (2) the influence of motivation toward the work performance of employees in PT. TWC Borobudur, Prambanan \& Ratu Boko (Persero), (3) the influence of work discipline toward the work performance of employees in PT. TWC Borobudur, Pramban an \& Ratu Boko (Persero), (4) the influence of leadership styles, motivation and work discipline simultaneously toward the work performance of employees in PT. TWC Borobudur, Prambanan \& Ratu Boko (Persero). The sample of this study was the employees of PT. Taman Wisata Candi Borobudur, Prambanan \& Ratu Boko (Persero), there were 130 employees in total, by using the technique of simple insidental sampling. The multiple linear regression model was used for collecting the data in this study. The test validity used in the study was confirmatory factor analysis. From the test result, there were 20 questions fallen, those were the items in questioning: the variable of leadership style with 4 questions in total; 7 questions on the variable of motivation; 6 questions on the variable of work discipline; and also 3 questions on work performance, from 22 questions in total and all of the reliable questions. The result from this study showed that the variable on leadership style (X1) had an positive effect toward the work performance of PT. TWC Borobudur, Prambanan \& Ratu Boko (Persero)'s employees. The variable of motivation (X2) influenced positively toward the work performance of the employees at PT. TWC Borobudur, Prambanan \& Ratu Boko (Persero). The variable of work discipline (x3) had positive effect on the work performance of the employees at PT. TWC Borobudur, Prambanan \& Ratu Boko (Persero). The variable of leadership style, motivation and work discipline altogether or simultaneously had a significant effect toward the work performance of employee at PT. TWC Borobudur, Prambanan \& Ratu Boko (Persero).
\end{abstract}

Keywords: Leadership Style, Motivation, Work Discipline, Work Performance.

\section{PENDAHULUAN}

Perkembangan bisnis saat ini yang pesat khususnya di sektor pariwisata dewasa ini mendorong perusahaaan atau organisasi untuk mengoptimalkan sumber daya yang dimiliki untuk menghadapi persaingan. Persaingan merupakan suatu tantangan yang harus dihadapi oleh setiap perusahan. Perusahaan harus mempersiapkan strategi yang kuat agar dapat mempertahankan posisi kompetitif ditengah persaingan melalui penentuan visi dan misi yang jelas serta bekerja dengan lebih efisien, efektif dan produktif. Pada berbagai bidang 
khususnya kehidupan berorganisasi, faktor manusia merupakan masalah utama disetiap kegiatan yang ada didalamnya. Organisasi merupakan kesatuan sosial yang dikoordinasikan secara sadar dengan sebuah batasan yang reaktif dapat diidentifikasikan.

Visi dan misi suatu perusahaan dapat tercapai apabila perusahaan mampu meningkatkan prestasi karyawan di perusahaan tersebut. Pada aspek bidang pekerjaan baik itu di instansi pemerintah maupun swasta selalu di butuhkan adanya karyawan yang terampil. Prestasi kerja dapat dikatakan sebagai sebuah informasi yang menunjukan tingkat kualiats dan kuantitas hasil kerja seseorang. Apabila karyawan mampu menyelesaikan tugastugasnya sesuai dengan standar kerja $\mathrm{m}$ aka ia dapat dikatakan berprestasi. Hal ini sesuai dengan pendapat Hasibuan (2012). Prestasi kerja adalah suatu hasil kerja yang dicapai oleh seseorang dalam melaksanakan tugas-tugas yang dibebankan kepadanya yang didasarkan atas kecakapan, pengalaman serta waktu.

Beberapa faktor yang dapat mempengaruhi prestasi kerja karyawan, yaitu: Pertama, adalah faktor disiplin kerja merupakan salah satu aspek yang mempengaruhi prestasi karyawan. Menurut Ardana (2011) disiplin kerja merupakan suatu sikap menghormati, menghargai, patuh, dan taat terhadap peraturan-peraturan yang berlaku, baik yang tertulis maupun yang tidak tertulis serta sanggup menjalankannya dan tidak mengelak untuk menerima sanksisanksinya. Iriani (2010) menambahkan bahwa kedisiplinan karyawan mutlak diperlukan agar seluruh aktivitas yang sedang dan akan dilaksanakan berjalan sesuai mekanisme yang telah ditentukan. Dengan kedisiplinan kerja maka, karyawan tidak akan melakukan tindakan-tindakan yang dapat merugikan perusahaan.

Kedua, adalah gaya kepemimpinan. Thoha (2010), gaya kepemimpinan adalah norma perilaku yang digunakan oleh seseorang pada saat orang tersebut mencoba memengaruhi perilaku orang lain untuk mencapai tujuannya. Brahmasari (2008), mnyebutkan kepemimpinan adalah suatu proses dimana seseorang dapat menjadi pemimpin melalui aktivitas yang terus menerus sehingga dapat mempengaruhi orang yangdipimpinnya untuk mencapai tujuan organisasi atau perusahaan. Gaya kepemimpinan yang sesuai dengan situasi dan kondisi akan mendorong karyawan untuk bekerja lebih bersemangat dalam menjalankan tugas dan kewajibannya.

Ketiga, adalah motivasi kerja. Menurut Sutrisno (2007) motivasi adalah suatu sikap atau dorongan yang berasal dari dalam diri seseorang untuk melakukan suatu aktivitas tertentu. Kepemimpinan di kantor improfisasi untuk memberikan motivasi dan menetapkan disiplin kerja kepada staff atau bawahannya, seperti kurang memberi masukan masukan positif kepada pegawai, kurang memberikan semangat kepada pegawai, kurang menghargai pendapat/masukan yang diberikan pegawai kepada atasan, kurang mencontohkan sikap disiplin.

Terkait dengan beberapa faktor di atas, peneliti telah melakukan observasi di PT. Taman Wisata Candi Borobudur, Prambanan \& Ratu Boko. PT. Taman Wisata Candi Borobudur, Prambanan \& Ratu Boko lahir sebagai bentuk kepedulian Pemerintah terhadap upaya melestarikan dan menjaga aset-aset peninggalan sejarah dan budaya. PT. Taman Wisata Candi Borobudur, Prambanan yang berdiri sejak tanggal 15 Juli 1980, diperluas cakupan pengelolaannya dengan masuknya 
kawasan Ratu Boko sebagai bagian dari manajemen PT. Taman sejak tanggal 3 Agustus 1994, sehingga perusahaan berubah nama menjadi PT. Taman Wisata Candi Borobudur, Prambanan \& Ratu Boko. Pada PT. Taman Wisata Candi Borobudur, Prambanan \& Ratu Bokoterdapat beberapa masalah.

Menurut Sigit Setiawan, salah satu staff SDM kantor PT. Taman Wisata Candi Borobudur, Prambanan \& Ratu Boko Banyaknya pegawai yang menyalahi atuan prosedur kerja seperti banyaknya pegawai yang telat masuk kantor dan pimpinan tidak memberikan teguran atau sanksi yang tegas kepada para pegawainya, dalam hal pekerjaan pimpinan kurang memberi perhatian atau arahan kepada bawahannya sehingga banyak pekerjaan yang tidak tepat waktu, tidak tercapainya target pendapatan perusahaan dalam beberapa bulan terakhir, pada saat apel pagi setiap hari senin dilaksanakan, banyak pegawai yang tidak mengikuti apel pagi, hali ini tidak mendapat perhatian khusus oleh pimpinan dan pimpinan tidak memberikan teguran atau sanksi yang tegas dalam menjalankan tugas kesehariannya pimpinannya.

Tujuan dari penelitian ini adalah: 1) untuk mengetahui pengaruh gaya kepemimpinan terhadap prestasi kerja pergawai PT. Taman Wisata Candi Borobudur, Prambanan dan Ratu Boko, 2) untuk mengetahui pengaruh motivasi terhadap prestasi kerja pergawai PT. Taman Wisata Candi Borobudur, Prambanan dan Ratu Boko, 3) untuk mengetahui pengaruh disiplin kerja terhadap prestasi kerja pergawai PT. Taman Wisata Candi Borobudur, Prambanan dan Ratu Boko dan 4) untuk mengetahui pengaruh gaya kepemimpinan, motivasi dan disiplin kerja secara simultan terhadap prestasi kerja pergawai PT.
Taman Wisata Candi Borobudur, Prambanan dan Ratu Boko.

\section{REVIEW LITERATUR DAN HIPOTESIS}

\section{Landasan Teori}

\section{Prestasi Kerja}

Menurut Sastrohadiwiryo (2002) yang dimaksud prestasi kerja adalah kinerja yang dicapai seorang tenaga kerja oleh seorang tenaga kerja dalam melaksanakan tugas dan pekerjaan yang diberikan kepadanya. Pada umumnya kerja seorang tenaga kerja antara lain dipengaruhi oleh kecakapan, keterampilan, pengalaman, dan kesungguhan tenaga kerja yang bersangkutan. Handoko (2008) ditegaskan motivasi seorang pengusaha/seseorang tidak sematamata meraih keuntungan sendiri, tetapi karena keinginan kuat berprestasi.

2. Gaya Kepemimpinan

Menurut Thoha (2010) gaya kepemimpinan merupakan norma perilaku yang digunakan oleh seseorang pada saat orang tersebut mencoba mempengaruhi perilaku orang lain seperti yang mereka lihat.

3. Motivasi

Menurut Hasibuan (2012) motivasi berasal dari kata latin movere, yang berarti dorongan atau daya penggerak. Motivasi dalam manajemen hanya ditunjukan pada sumber daya manusia umumnya dan khususnya kepada para bawahan atau pengikut. Motivasi mempersoalkan bagaimana caranya mengarahkan daya dan potensi bawahan, agar mau bekerja sama secara produktif, berhasil mencapai dan mewujudkan tujuan yang telah ditentukan.

Motivasi adalah serangkaian sikap dan nilai-nilai yang mempengaruhi individu untuk mencapai hal yang spesifik sesuai 
dengan tujuan individu. Sikap dan nilai-nilai tersebut merupakan suatu yang invisibel yang memberikan kekuatan untuk mendorong individu bertingkah laku dalam mencapai tujuan (Veithzal, 2010).

Bangun (2012) menambahkah bahwa motivasi adalah suatu tindakan untuk memengaruhi orang lain agar berperilaku (to behave) secara teratur. Motivasi merupakan suatu tugas sebagai manajer untuk memengaruhi orang lain atau karyawan dalam suatu perusahaan.

\section{Disiplin Kerja}

Menurut Hasibuan (2012) disiplin kerja adalah kesadaran dan kesediaan seseorang menaati semua peraturan perusahaan dan norma-norma sosial yang berlaku. Kesadaran adalah sikap seseorang yang secara sukarela mentaati semua peraturan dan sadar akan tugas dan tanggung jawabnya. Jadi, dia akan mematuhi/mengerjakan semua tugasnya dengan baik, bukan atas paksaan. Kesediaan adalah suatu sikap, tingkah laku, dan perbuatan seseorang yang sesuai dengan peraturan perusahaan, baik yang tertulis maupun tidak.

Veithzal (2010) menjelaskan bahwa disiplin kerja adalah suatu alat yang digunakan oleh para manajer untuk berkomunikasi dengan karyawan agar mereka bersedia untuk mengubah suatu perilaku serta sebagai suatu upaya untuk meningkatkan kesadaran dan kesediaan seseorang mentaati semua peraturan perusahaan dan norma-norma sosial yang berlaku. Mangkunegara (2010) menambahkan bahwa disiplin kerja dapat diartikan sebagai pelaksanaan manajemen untuk memperteguh pedoman-pedoman organisasi.

\section{Penelitian Terdahulu}

Dinar (2014) melakukan penelitian dengan judul "Pengaruh Motivasi Kerja Terhadap Prestasi Kerja Karyawan CV. Triaji Kedunguter Banyumas". Hasilnya motivasi kerja berpengaruh positif, baik secara simultan maupun parsial terhadap prestasi karyawan.

Anggraini (2017) melakukan penelitian dengan judul "Pengaruh Gaya Kepemimpinan dan Motivasi Terhadap Prestasi Kerja Pegawai Kantor Direktorat Jendral Perbendaharaan Kota Kupang". Hasilnya gaya kepemimpinan dan motivasi kerja berpengaruh positif, baik secara simultan maupun parsial terhadap prestasi pegawai.

Sariah (2017) melakukan penelitian dengan judul "Pengaruh Disiplin Kerja Terhadap Prestasi Kerja Karyawan PT. multimas Nabati Ashan". Hasilnya disiplin kerja berpengaruh positif, baik secara simultan maupun parsial terhadap kinerja pegawai.

\section{Hipotesis}

H1: Terdapat pengaruh positif antara gaya kepemimpinan terhadap prestasi kerja pegawai.

$\mathrm{H} 2$ : Terdapat pengaruh positif antara motivasi terhadap prestasi kerja pegawai.

H3: Terdapat pengaruh positif antara disiplin kerja terhadap prestasi kerja pegawai.

H4: Terdapat pengaruh positif antara gaya kepemimpinan, motivasi dan disiplin kerja terhadap prestasi kerja pegawai secara simultan.

\section{METODE PENELITIAN}

\section{Populasi dan Sampel}

Populasi adalah wilayah generalisasi yang terdiri atas objek atau subjek yang mempunyai kualitas dan karakteristik tertentu yang ditetapkan oleh peneliti 
untuk dipelajari dan kemudian ditarik kesimpulannya (Sugiyono, 2010). Penulis melakukan penelitian pada kantor PT. Taman Wisata Candi Ratu Boko yang beralamat di Bokoharjo, Prambanan, Sleman, sehinga populasi penelitian ini adalah seluruh pegawai kantor PT. Taman Wisata Candi Prambanan \& Ratu Boko.

Sampel dalam penelitian ini adalah karyawan PT. Taman Wisata Candi Ratu Boko. Dalam penelitian ini penulis mengambil sampel dengan menggunakan non probability sampling dengan pendekatan teknik insidental sampling. Menurut Sugiyono (2010) bahwa sampel insidental adalah teknik penentuan sample berdasarkan kebetulan yaitu siapa saja secara kebetulan/insidental bertemu dengan peneliti dapat digunakan sebagai sampel, bila dipandang orang yang kebetulan ditemui itu cocok sebagai sumber data.

\section{Uji Instrumen}

1. Uji Validitas

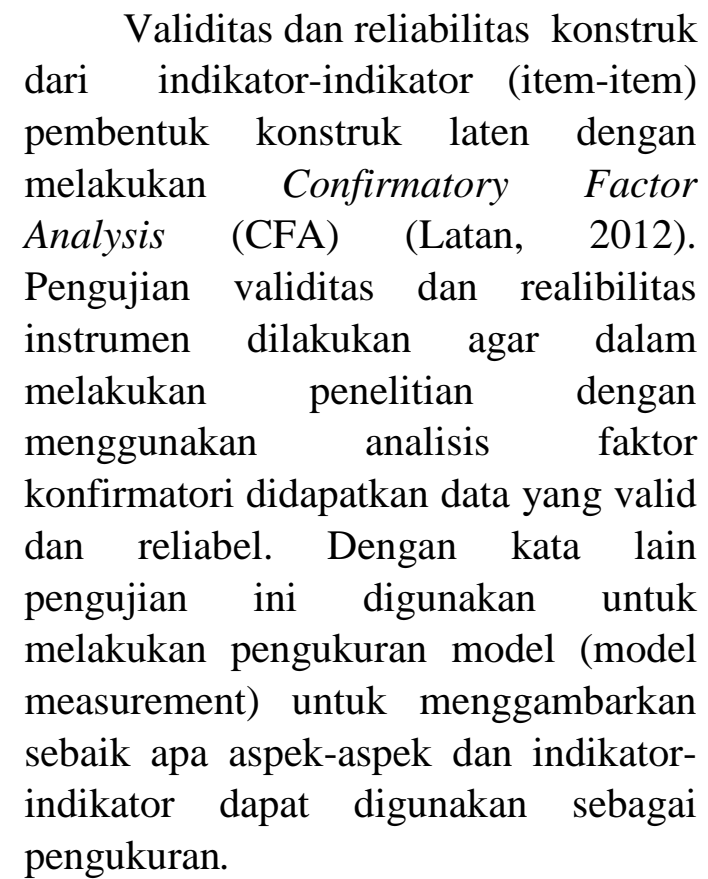

Second order confirmatory factor analysis (2nd Order CFA) adalah model pengukuran yang terdiri dari dua tingkat. Tingkat pertama analisis dilakukan dari konstruk laten aspek ke indikator-indikatornya dan kedua analisis dilakukan dari konstruk laten ke konstruk aspeknya (Latan, 2012). Menurut Hair, et al., (2010), melalui CFA tidak hanya dapat dilakukan pengujian validitas konstrak (Construct Validity), tetapi juga reliabilitas konstruk (Construct Reliability). Pengujian 2nd Order CFA ini dilakukan dengan melihat nilai muatan faktor $(>0.5)$ dan nilai $t$ hitung $(>1,96)$. Bobot muatan faktor sebesar 0,50 atau lebih dianggap memiliki validitas yang cukup kuat untuk menjelaskan konstruk laten (Hair, et al., 2010). Instrument memiliki convergent validity jika item pengukuran memiliki faktor loading lebih besar dari 0,4. Hair et al., (2010) juga menyatakan bahwa faktor loading lebih besar 0,3 dapat dipertimbangkan sebagai batas minimal dan bila faktor loading lebih besar dari 0,5 maka diterima secara signifikan.

\section{Uji Reliabilitas}

Uji reliabilitas sebenarnya adalah alat untuk mengukur suatu kuesioner yang merupakan indikator dari variabel atau konstruk. Suatu kuesioner dikatakan reliabel jika jawaban seseorang terhadap pernyataan adalah konsisten atau stabil dari waktu ke waktu (Ghozali, 2011). Dalam penelitian ini, uji reliabilitas dilakukan dengan menggunakan teknik Cronbach's Alpha dengan bantuan software SPS (Ghozali, 2011). Cronbach's Alpha adalah koefisien keandalan yang menunjukkan seberapa baik item dalam suatu kumpulan secara positif berkorelasi satu sama lain. Konsistensi jawaban ditunjukan oleh nilai rule of thumb atau tingginya cronbach's alpha, dengan nilai alpha 
harus lebih besar dari 0,7 meskipun nilai 0,6 masih dapat diterima (Hair et al., 2010).

\section{Analisis Regresi Linier Berganda}

Analisis regresi linear berganda merupakan teknik analisis data yang digunakan dalam menganalisis pengaruh variabel bebas terhadap variabel terikat, dimana:

$\mathrm{Y}=\alpha+\beta 1 \mathrm{X} 1+\beta 2 \mathrm{X} 2+\beta 3 \mathrm{X} 3$

Keterangan:

$$
\begin{array}{ll}
\mathrm{Y} & =\text { Prestasi kerja pegawai } \\
\mathrm{A} & =\text { Konstanta } \\
\beta 1, \beta 2, \beta 3 & =\text { Koefisien variabel } \\
& \quad \text { independen } \\
\mathrm{X} 1 & =\text { Gaya Kepemimpinan } \\
\mathrm{X} 2 & =\text { Motivasi } \\
\mathrm{X} 3 & =
\end{array}
$$

\section{Uji Parsial (Uji T)}

Pengujian signifikansi digunakan untuk mengetahui apakah hasil perhitungan korelasi sederhana signifikan atau tidak. Menurut Sugiyono (2010) pengujian signifikansi digunakan untuk menentukan boleh atau tidaknya pemberlakuan hasil perhitungan korelasi yang didapat pada korelasi (generalisasi). Pengujian korelasi signifikansi sederhana dilakukan dengan uji signifikansi t, rumusnya sebagai beikut:

$$
t=\frac{r \sqrt{n-2}}{\sqrt{1-r^{2}}}
$$

Keterangan:

$\mathrm{t}$ : Nilai $\mathrm{t}$

$\mathrm{r}$ : koefisien korelasi antara variabel $\mathrm{X}$ dan $\mathrm{Y}$

$\mathrm{n}$ : jumlah responden

Nilai t hitung tersebut kemudian dibandingkan dengan harga $\mathrm{t}$ tabel (taraf kesalahan 5\% uji dua pihak dengan $\mathrm{dk}=\mathrm{n}-2)$. Apabila diperoleh hasil $\mathrm{t}$ hitung $>\mathrm{t}$ tabel, maka Ho ditolak dan Ha diterima atau dapat dinyatakan bahwa hubungan variabel $\mathrm{X}$ dengan $\mathrm{Y}$ signifikan serta dapat digeneralisasikan pada populasi penelitian.

\section{Uji Simultan (Uji F)}

Uji statistik $F$ pada dasarnya menunjukkan apakah semua variabel independen atau bebas yang dimasukkan dalam model mempunyai pengaruh secara bersamasama atau simultan terhadap variabel dependen atau terikat. Dengan membandingkan nilai $\mathrm{F}$ hitung > F tabel, maka $\mathrm{H} 0$ ditolak dan menerima Ha. Dengan kata lain menyatakan bahwa variabel independen secara serentak dan signifikan mempengaruhi variabel dependen. Selain itu juga bisa dengan menggunakan uji signifikansi. Jika nilai signifikansi lebih kecil dari 0,05, maka ini berarti ada alasan yang untuk menerima hipotesis satu (H1) dan menolak hipotesis nol (H0), demikian pula sebaliknya. (Ghozali, 2011).

\section{Uji Koefisien Determinasi}

Koefisien Determinasi (R2) pada intinya mengukur seberapa jauh kemampuan model dalam menerangkan variasi variabel dependen. Nilai koefisien determinasi adalah antara nol dan satu. Nilai R2 yang kecil berarti kemampuan variabel independen dalam menjelaskan variasi variabel dependen amat terbatas. Nilai yang mendekati satu berarti variabel independen memberikan hampir semua informasi yang dibutuhkan untuk memprediksi variasi variabel dependen. Namun penggunaan koefisien determinasi memiliki kelemahan yaitu bias terhadap jumlah variabel independen yang dimasukkan ke dalam model, 
setiap tambahan satu variabel independen maka R2 pasti meningkat tidak perduli apakah variabel tersebut berpengaruh secara signifikan terhadap variabel dependen. Oleh karena itu banyak peneliti menganjurkan untuk menggunakan nilai Adjusted R2 saat mengevaluasi model regresi terbaik (Ghozali, 2011).

\section{HASIL PENELITIAN DAN PEMBAHASAN}

\section{Hasil Analisis Responden}

Dari jumlah 150 kuesioner yang disebarkan tersebut diperoleh data 130 responden. Kuesioner yang disebarkan dalam penelitian ini terdiri dari 22 butir pertanyaan yang mewakili 4 variabel. 22 butir pertanyaan tersebut dari 6 butir pertanyaan yang mewakili dua variabel gaya kepemimpinan dan disiplin kerja dan 5 butir pertanyaan yang mewakili dua variael motivasi dan prestasi kerja.

Tabel Data Responden Berdasarkan Jenis Kelamin

\begin{tabular}{|c|c|c|}
\hline Jenis Kelamin & Frequency & Perrcent \% \\
\hline Laki-laki & 112 & $86,2 \%$ \\
\hline Perempuan & 18 & $13,8 \%$ \\
\hline Jumlah & 130 & $100 \%$ \\
\hline
\end{tabular}

Bedasarkan tabel di atas, menunjukan bahwa sebagian besar responden berjenis kelamin laki-laki yaitu sebanyak 112 orang $(86,2 \%)$ dan responden berjenis kelamin perempuan sebesar 18 orang $(13,8 \%)$.
Tabel Data Responden Berdasarkan Usia

\begin{tabular}{|c|c|c|}
\hline Usia & Frequency & Percent \% \\
\hline $31-35$ tahun & 2 & $1,5 \%$ \\
\hline $36-40$ tahun & 18 & $13,8 \%$ \\
\hline$>40$ tahun & 110 & $84,7 \%$ \\
\hline Jumlah & 130 & $100 \%$ \\
\hline
\end{tabular}

Bedasarkan tabel di atas, menunjukan bahwa sebagian besar responden berusia > 40 tahun sebanyak 110 orang $(84,7 \%)$ kemudian usia $36-40$ tahun sebesar 18 orang $(13,8 \%)$ dan usia 31-35 tahun sebesar 2 orang $(1,5 \%)$.

Tabel Data Responden Berdasarkan Pendidikan Terakhir

\begin{tabular}{|c|c|c|}
\hline Pendidikan Terakhir & frequency & Perrcent\% \\
\hline Sarjana & 18 & $13,8 \%$ \\
\hline SMA/SMK & 112 & $86,2 \%$ \\
\hline Jumlah & 130 & $100 \%$ \\
\hline
\end{tabular}

Bedasarkan tabel di atas, menunjukan bahwa sebagian besar responden berpendidikan terakhir SMA/ SMK yaitu sebanyak 112 orang $(86,2 \%)$ dan responden berpendidikan sarjana sebesar 18 orang $(13,8 \%)$.

Tabel Data Responden Berdasarkan Lama Bekerja

\begin{tabular}{|c|c|c|}
\hline Lama Bekerja & Frequency & Perrcent \% \\
\hline$>6$ tahun & 130 & $100 \%$ \\
\hline Jumlah & 130 & $100 \%$ \\
\hline \multicolumn{2}{|c|}{ Bedasarkan tabel di atas, }
\end{tabular}
menunjukan bahwa semua responden telah bekerja > 6 tahun yaitu 130 orang $(100 \%)$. 
Hasil Penelitian

1. Hasil Uji Validitas
a. Hasil
Uji Validitas
Gaya
Kepemimpinan

Tahap 1

\begin{tabular}{|c|c|}
\hline KMO &, 674 \\
\hline $\begin{array}{c}\text { Bartlett's Test } \\
\text { of Sphericity } \\
\text { Sig. }\end{array}$ &, 000 \\
\hline
\end{tabular}

\begin{tabular}{|c|c|c|c|}
\hline \multirow{2}{*}{ Pertanyaan } & \multicolumn{3}{|c|}{ Component } \\
\cline { 2 - 4 } & 1 & 2 & 3 \\
\hline GK 1 &,- 199 &,- 204 &, 866 \\
\hline GK 2 &, 744 &,- 320 &, 189 \\
\hline GK 3 &, 548 &,- 616 &, 165 \\
\hline GK 4 &, 780 &,- 320 &, 120 \\
\hline GK 5 &, 788 &,- 018 &, 048 \\
\hline GK 6 &, 739 &, 086 &,- 034 \\
\hline GK 7 &, 674 &,- 006 &,- 297 \\
\hline GK 8 &, 579 &, 489 &, 057 \\
\hline GK 9 &, 077 &, 799 &, 478 \\
\hline GK 10 &, 674 &, 586 &,- 052 \\
\hline
\end{tabular}

Maka dari hasil output yang ada pada tabel di atas, dari sepuluh itempertanyaan dalam kuesioner yang ada menunjukan tidak valid dengan nilai yang rendah, sehingga item pertanyaan GK 1 dan GK 9 harus dihilangkan agar menghasilkan satu komponen yang valid. Item pertanyaan yang dihilangkan dapat dilihat dari nilai anti-image correlation terkecil terdapat pada item pertanyaan nomer 1 dan 9 . Setelah penghapusan pertanyaan GK 1 dan GK 9 hasil komponen yang baru seperti yang ada pada tabel berikut:
Tahap 2

\begin{tabular}{|l|l|}
\hline KMO &, 726 \\
\hline $\begin{array}{l}\text { Bartlett's Test } \\
\text { of Sphericity } \\
\text { Sig. }\end{array}$ &, 000 \\
\hline
\end{tabular}

\begin{tabular}{|c|c|c|}
\hline \multirow{2}{*}{ Pertanyaan } & \multicolumn{2}{|c|}{ Component } \\
\cline { 2 - 3 } & 1 & 2 \\
\hline GK 2 &, 760 &,- 314 \\
\hline GK 3 &, 572 &,- 671 \\
\hline GK 4 &, 790 &,- 381 \\
\hline GK 5 &, 791 &, 053 \\
\hline GK 6 &, 736 &, 139 \\
\hline GK 7 &, 673 &, 191 \\
\hline GK 8 &, 559 &, 433 \\
\hline GK 10 &, 653 &, 626 \\
\hline
\end{tabular}

Dari hasil output yang ada pada tabel di atas, dari 7 item pertanyaan dalam kuesioner yang ada menunjukan tidak valid, sehingga item pertanyaan GK 3 dan 8 harus dihilangkan agar menghasilkan satu komponen yang valid. Itempertanyaan yang dihilangkan dapat dilihat dari nilai anti-image correlationterkecil terdapat pada item pertanyaan nomer 3 dan 8. Setelah penghapusan pertanyaan Gk 3 dan GK 8 hasil komponen yang baru seperti yang ada pada tabel berikut:

Tahap 3

\begin{tabular}{|l|l|}
\hline KMO &, 838 \\
\hline $\begin{array}{l}\text { Bartlett's Test } \\
\text { of Sphericity } \\
\text { Sig. }\end{array}$ &, 000 \\
\hline
\end{tabular}




\begin{tabular}{|c|c|}
\hline Pertanyaan & Component \\
\cline { 2 - 2 } & 1 \\
\hline GK 2 &, 763 \\
\hline GK 4 &, 751 \\
\hline GK 5 &, 803 \\
\hline GK 6 &, 799 \\
\hline GK 7 &, 690 \\
\hline GK 10 &, 676 \\
\hline
\end{tabular}

Dari tabel di atas, hasil proses olah data menggunakan program SPSS 20 bahwa nilai KMO dari variable gaya kepemimpinan adalah $0,838>0,50$ dengan demikian nilai KMO terpenuhi karena nilai KMO > 0,50 dan factor loading dari setiap butir pertanyaan > 0,40 dan lebih besar dari 0,50. Maka dapat disimpulkan bahwa 6 butir pertanyaan di atas adalah variabel gaya kepemimpinan yang valid.

b. Hasil Uji Validitas Motivasi

Tahap 1

\begin{tabular}{|l|l|}
\hline KMO &, 442 \\
\hline $\begin{array}{l}\text { Bartlett's Test } \\
\text { of Sphericity } \\
\text { Sig. }\end{array}$ &, 000 \\
\hline
\end{tabular}

\begin{tabular}{|c|c|c|c|c|c|}
\hline Pertanyaan & \multicolumn{5}{|c|}{ Component } \\
\cline { 2 - 6 } & 1 & 2 & 3 & 4 & 5 \\
\hline M1 &, 099 &, 693 &,- 024 & $-; 94$ &, 409 \\
\hline M2 &, 606 & -395 &,- 015 &, 319 &, 323 \\
\hline M3 &, 330 &,- 129 &, 551 & $-; 366$ & $-; 310$ \\
\hline M4 &, 671 & -265 &, 038 &, 156 &, 274 \\
\hline M5 &, 704 & -310 &, 249 &, 070 &, 330 \\
\hline
\end{tabular}

\begin{tabular}{|c|c|c|c|c|c|}
\hline \multirow{2}{*}{ Pertanyaan } & \multicolumn{5}{|c|}{ Component } \\
\cline { 2 - 6 } & 1 & 2 & 3 & 4 & 5 \\
\hline M6 & -367 &, 125 &, 193 &, 547 &,- 246 \\
\hline M7 &, 020 &, 490 &,- 606 &, 287 &, 255 \\
\hline M8 &, 219 &, 605 &, 587 &,- 249 &, 169 \\
\hline M9 &, 687 &, 396 &, 186 &, 420 &,- 061 \\
\hline M10 &, 490 &, 414 &, 126 &, 416 &,- 442 \\
\hline M11 &, 679 &,- 127 &,- 372 &,- 420 &,- 314 \\
\hline M12 &, 712 &, 173 &,- 496 & -204 &,- 295 \\
\hline
\end{tabular}

Dari hasil output yang ada pada tabel di atas, dari dua belas item pertanyaan dalam kuesioner yang ada menunjukan tidak valid dengan nilai yang rendah, sehingga item pertanyaan M1, M3 dan M8 harus dihilangkan agar menghasilkan satu komponen yang valid. Item pertanyaan yang dihilangkan dapat dilihat dari nilai anti-image correlation terkecil terdapat pada item pertanyaan nomer 1,3 dan 8 . Setelah penghapusan pertanyaan M1, M3 dan M8 hasil komponen yang baru seperti yang ada pada tabel berikut:

Tahap 2

\begin{tabular}{|l|l|}
\hline KMO &, 573 \\
\hline $\begin{array}{l}\text { Bartlett's Test } \\
\text { of Sphericity } \\
\text { Sig. }\end{array}$ &, 000 \\
\hline
\end{tabular}

\begin{tabular}{|c|c|c|c|}
\hline \multirow{2}{*}{ Pertanyaan } & \multicolumn{3}{|c|}{ Component } \\
\cline { 2 - 4 } & 1 & 2 & 3 \\
\hline M2 &, 641 &,- 244 &, 393 \\
\hline M4 &, 686 &,- 205 &, 275 \\
\hline M5 &, 697 &,- 342 &, 416 \\
\hline M6 &,- 363 &, 428 &, 430 \\
\hline M7 &, 068 &, 563 &,- 251 \\
\hline M9 &, 672 &, 510 &, 271 \\
\hline
\end{tabular}

\begin{tabular}{|c|c|c|c|}
\hline M10 &, 476 &, 685 &, 134 \\
\hline M11 &, 685 &,- 188 &,- 572 \\
\hline M12 &, 737 &, 153 &,- 558 \\
\hline
\end{tabular}


Dari hasil output yang ada pada tabel di atas, dari 9 item pertanyaan dalam kuesioner yang ada menunjukan tidak valid, sehingga item pertanyaan M7 dan 11 harus dihilangkan agar menghasilkan satu komponen yang valid. Item pertanyaan yang dihilangkan dapat dilihat dari nilai anti-image correlation terkecil terdapat pada item pertanyaan nomer 7 dan 11. Setelah penghapusan pertanyaan M7 dan M11 hasil komponen yang baru seperti yang ada pada tabel berikut:

Tahap 3

\begin{tabular}{|l|l|}
\hline KMO &, 686 \\
\hline $\begin{array}{l}\text { Bartlett's Test } \\
\text { of Sphericity } \\
\text { Sig. }\end{array}$ &, 000 \\
\hline
\end{tabular}

\begin{tabular}{|c|c|c|c|}
\hline \multirow{2}{*}{ Pertanyaan } & \multicolumn{3}{|c|}{ Component } \\
\cline { 2 - 4 } & 1 & 2 & 3 \\
\hline M2 &, 685 &,- 344 &, 370 \\
\hline M4 &, 712 &,- 284 &, 168 \\
\hline M5 &, 758 &,- 358 &, 195 \\
\hline M6 &,- 297 &, 491 &, 731 \\
\hline M9 &, 742 &, 481 &, 078 \\
\hline M10 &, 531 &, 723 &,- 068 \\
\hline M12 &, 602 &, 189 &,- 541 \\
\hline
\end{tabular}

Dari hasil output yang ada pada tabel di atas, dari 7 item pertanyaan dalam kuesioner yang ada menunjukan tidak valid, sehingga item pertanyaan M 6 dan 10 harus dihilangkan agar menghasilkan satu komponen yang valid. Item pertanyaan yang dihilangkan dapat dilihat dari nilai anti-image correlation terkecil terdapat pada item pertanyaan nomer 6 dan 10. Setelah penghapusan pertanyaan M6 dan M10 hasil komponen yang baru seperti yang ada pada tabel berikut:
Tahap 4

\begin{tabular}{|l|l|}
\hline KMO &, 756 \\
\hline $\begin{array}{l}\text { Bartlett's Test } \\
\text { of Sphericity } \\
\text { Sig. }\end{array}$ &, 000 \\
\hline
\end{tabular}

\begin{tabular}{|c|c|}
\hline Pertanyaan & Component \\
\cline { 2 - 2 } & 1 \\
\hline M2 &, 768 \\
\hline M4 &, 754 \\
\hline M5 &, 802 \\
\hline M9 &, 683 \\
\hline M12 &, 543 \\
\hline
\end{tabular}

Dari tabel di atas, hasil proses olah data menggunakan program SPSS 20 bahwa nilai KMO dari variabel motivasi adalah $0,756>$ 0,50 dengan demikian nilai KMO terpenuhi karena nilai $\mathrm{KMO}>0,50$ dan factor loading dari setiap butir pertanyaan >0,50. Maka dapat disimpulkan bahwa 5 butir pertanyaan di atas adalah variabel motivasi yang valid.

c. Hasil Uji Validitas Disiplin Kerja

Tahap 1

\begin{tabular}{|l|l|}
\hline KMO &, 614 \\
\hline $\begin{array}{l}\text { Bartlett's Test } \\
\text { of Sphericity } \\
\text { Sig. }\end{array}$ &, 000 \\
\hline
\end{tabular}

\begin{tabular}{|c|c|c|c|c|}
\hline & \multicolumn{4}{|c|}{ Component } \\
\hline Pertanyaan & 1 & 2 & 3 & 4 \\
\hline DK1 &, 474 &,- 500 &, 154 &,- 466 \\
\hline DK2 &, 741 &,- 438 &,- 252 &,- 087 \\
\hline DK3 &, 614 &, 351 &,- 096 &,- 325 \\
\hline DK4 &, 558 &, 526 &,- 307 &,- 135 \\
\hline DK5 &, 412 &,- 428 &,- 378 &, 291 \\
\hline DK6 &, 798 &,- 252 &,- 029 &,- 043 \\
\hline DK7 &, 677 &, 182 &,- 245 &, 296 \\
\hline DK8 &, 363 &, 349 &, 555 &,- 385 \\
\hline DK9 &, 128 &,- 177 &, 651 &, 434 \\
\hline DK10 &, 548 &,- 253 &, 410 &,- 032 \\
\hline DK11 &, 710 &, 107 &, 218 &, 417 \\
\hline DK12 &, 401 &, 662 &, 060 &, 201 \\
\hline
\end{tabular}


Dari hasil output yang ada pada tabel di atas, dari 12 item pertanyaan dalam kuesioner yang ada menunjukan tidak valid dengan nilai yang rendah, sehingga item pertanyaan DK5, DK8 dan DK9 harus dihilangkan agar menghasilkan satu komponen yang valid. Item pertanyaan yang dihilangkan dapat dilihat dari nilai anti-image correlation terkecil terdapat pada itempertanyaan nomer 5, 8 dan 9 . Setelah penghapusan pertanyaan DK5, DK8 dan DK9 hasil komponen yang baru seperti yang ada pada tabel berikut:

Tahap 2

\begin{tabular}{|l|l|}
\hline KMO &, 673 \\
\hline $\begin{array}{l}\text { Bartlett's Test } \\
\text { of Sphericity } \\
\text { Sig. }\end{array}$ &, 000 \\
\hline
\end{tabular}

\begin{tabular}{|c|c|c|c|}
\hline \multirow{2}{*}{ Pertanyaan } & \multicolumn{3}{|c|}{ Component } \\
\cline { 2 - 4 } & 1 & 2 & 3 \\
\hline DK1 &, 454 &,- 661 &,- 016 \\
\hline DK2 &, 733 &,- 412 &,- 127 \\
\hline DK3 &, 628 &, 291 &,- 356 \\
\hline DK4 &, 568 &, 539 &,- 494 \\
\hline DK6 &, 815 &,- 277 &,- 059 \\
\hline DK7 &, 710 &, 257 &,- 108 \\
\hline DK10 &, 553 &,- 349 &, 205 \\
\hline DK11 &, 684 &, 132 &, 578 \\
\hline DK12 &, 426 &, 606 &, 518 \\
\hline
\end{tabular}

Dari hasil output yang ada pada tabel di atas, dari 9 item pertanyaan dalam kuesioner yang ada menunjukan tidak valid mempunyai nilai lebih kecil dari 0.05, sehingga item pertanyaan DK1, DK4 dan DK12 harus dihilangkan agar menghasilkan satu komponen yang valid. Item pertanyaan yang dihilangkan dapat dilihat dari nilai anti-image correlation terkecil terdapat pada item pertanyaan nomer 1, 4 dan 12 . Setelah penghapusan pertanyaan DK1, DK4 dan DK12 hasil komponen yang baru seperti yang ada pada tabel berikut:

Tahap 3

\begin{tabular}{|l|l|}
\hline KMO &, 790 \\
\hline $\begin{array}{l}\text { Bartlett's Test of } \\
\text { Sphericity Sig. }\end{array}$ &, 000 \\
\hline
\end{tabular}

\begin{tabular}{|c|c|}
\hline Pertanyaan & Component \\
\cline { 2 - 2 } & 1 \\
\hline DK2 &, 765 \\
\hline DK3 &, 594 \\
\hline DK6 &, 850 \\
\hline DK7 &, 680 \\
\hline DK10 &, 643 \\
\hline DK11 &, 673 \\
\hline
\end{tabular}

Dari tabel di atas, hasil proses olah data menggunakan program SPSS 20 bahwa nilai KMO dari variabel disiplin kerja adalah 0,790 > 0,50 dengan demikian nilai KMO terpenuhi karena nilai KMO > 0,50 dan factor loading dari setiap butir pertanyaan > 0,50. Maka dapat disimpulkan bahwa 6 butir pertanyaan di atas adalah variabel disiplin kerja yang valid.

d. Hasil Uji Validitas Prestasi Kerja

Tahap 1

\begin{tabular}{|l|l|}
\hline KMO &, 618 \\
\hline $\begin{array}{l}\text { Bartlett's Test of } \\
\text { Sphericity Sig. }\end{array}$ &, 000 \\
\hline
\end{tabular}




\begin{tabular}{|c|c|c|c|}
\hline & \multicolumn{3}{|c|}{ Component } \\
\hline Pertanyaan & 1 & 2 & 3 \\
\hline PK1 &, 593 &,- 408 &, 583 \\
\hline PK2 &, 472 &, 075 &,- 045 \\
\hline PK3 &, 687 &,- 493 &, 205 \\
\hline PK4 &, 668 &, 355 &, 492 \\
\hline PK5 &, 793 &, 477 &,- 124 \\
\hline PK6 &, 556 &, 678 &,- 108 \\
\hline PK7 &, 636 &,- 271 &,- 558 \\
\hline PK8 &, 719 &,- 381 &,- 390 \\
\hline
\end{tabular}

Dari hasil output yang ada pada tabel di atas, dari delapan item pertanyaan dalam kuesioner yang ada menunjukan tidak valid dengan nilai yang rendah, sehingga item pertanyaan PK6 harus dihilangkan agar menghasilkan satu komponen yang valid. Item pertanyaan yang dihilangkan dapat dilihat dari nilai anti-image correlation terkecil terdapat pada item pertanyaan nomer 6. Setelah penghapusan pertanyaan PK6 hasil komponen yang baru seperti yang ada pada tabel berikut:

\section{Tahap 2}

\begin{tabular}{|l|l|}
\hline KMO &, 647 \\
\hline $\begin{array}{l}\text { Bartlett's Test } \\
\text { of Sphericity } \\
\text { Sig. }\end{array}$ &, 000 \\
\hline
\end{tabular}

\begin{tabular}{|c|c|c|c|}
\hline \multirow{2}{*}{ Pertanyaan } & \multicolumn{3}{|c|}{ Component } \\
\cline { 2 - 4 } & 1 & 2 & 3 \\
\hline PK1 &, 663 &, 266 &,- 553 \\
\hline PK2 &, 473 &, 150 &, 387 \\
\hline PK3 &, 737 &,- 150 &,- 517 \\
\hline PK4 &, 624 &, 656 &, 024 \\
\hline PK5 &, 714 &, 262 &, 522 \\
\hline PK7 &, 664 &,- 547 &, 223 \\
\hline PK8 &, 760 &,- 487 &, 038 \\
\hline
\end{tabular}

Dari hasil output yang ada pada tabel di atas, dari tujuh item pertanyaan dalam kuesioner yang ada menunjukan tidak valid, sehingga item pertanyaan PK4 harus dihilangkan agar menghasilkan satu komponen yang valid. Item pertanyaan yang dihilangkan dapat dilihat dari nilai anti-image correlation terkecil terdapat pada item pertanyaan nomer 4. Setelah penghapusan perta nyaan PK4 hasil component yang baru seperti yang ada pada tabel berikut:

Tahap 3

\begin{tabular}{|l|l|}
\hline KMO &, 683 \\
\hline $\begin{array}{l}\text { Bartlett's Test } \\
\text { of Sphericity } \\
\text { Sig. }\end{array}$ &, 000 \\
\hline
\end{tabular}

\begin{tabular}{|c|c|c|}
\hline \multirow{2}{*}{ Pertanyaan } & \multicolumn{2}{|c|}{ Component } \\
\cline { 2 - 3 } & 1 & 2 \\
\hline PK1 &, 627 &,- 570 \\
\hline PK2 &, 483 &, 369 \\
\hline PK3 &, 756 &,- 511 \\
\hline PK5 &, 648 &, 506 \\
\hline PK7 &, 733 &, 253 \\
\hline PK8 &, 823 &, 063 \\
\hline
\end{tabular}

Dari hasil output yang ada pada tabel di atas, dari enam item pertanyaan dalam kuesioner yang ada menunjukan tidak valid, sehingga item pertanyaan PK1 harus dihilangkan agar menghasilkan satu komponen yang valid. Item pertanyaan yang dihilangkan dapat dilihat dari nilai anti-image correlation terkecil terdapat pada item pertanyaan nomer 1 . Setelah penghapusan pertanyaan PK1 hasil komponen yang baru seperti yang ada pada tabel berikut:

Tahap 4

\begin{tabular}{|l|l|}
\hline KMO &, 703 \\
\hline $\begin{array}{l}\text { Bartlett's Test } \\
\text { of Sphericity } \\
\text { Sig. }\end{array}$ &, 000 \\
\hline
\end{tabular}




\begin{tabular}{|c|c|}
\hline Pertanyaan & Component \\
\cline { 2 - 2 } & 1 \\
\hline PK2 &, 499 \\
\hline PK3 &, 685 \\
\hline PK5 &, 684 \\
\hline PK7 &, 788 \\
\hline PK8 &, 860 \\
\hline
\end{tabular}

Dari tabel di atas, hasil proses olah data menggunakan program SPSS 20 bahwa nilai KMO dari variabel prestasi kerja adalah 0,703 $>0,50$ dengan demikian nilai $\mathrm{KMO}$ terpenuhi karena nilai $\mathrm{KMO}>0,50$ dan factor loading dari setiap butir pertanyaan > 0,40 dan lebih besar dari 0,50. Maka dapat disimpulkan bahwa 5 butir pertanyaan di atas adalah variabel prestasi kerja yang valid.

2. Hasil Uji Reliabilitas

\begin{tabular}{|c|c|c|c|}
\hline$N_{0}$ & Variable & $\begin{array}{c}\text { Cronbach's } \\
\text { Alpha }\end{array}$ & Hasil \\
\hline 1 & Gaya Kepemimpinan & 0,836 & Reliable \\
\hline 2 & Motivasi & 0,702 & Reliable \\
\hline 3 & Disiplin Kerja & 0,777 & Reliable \\
\hline 4 & Prestasi Kerja & 0,751 & Reliable \\
\hline
\end{tabular}

a. Gaya kepemimpinan, dari hasil uji cronbach alpha yang dilakukan termasuk data yang reliabel. Dari setiap butir jawaban memiliki korelasi antara jawaban dengan peryataan yang ada. Didukung dengan nilai cronbach alpha yang dihasilkan yaitu 0,836 lebih besar dari 0,6.

b. Motivasi, nilai yang dihasilkan oleh variabel ini sebesar 0,702 dimana sesuai dengan ketentuan nilai 0,702 lebih besar dari 0,6 sehingga hasil dari variabel motivasi dalam pengujian yaitu reliabel. Dalam variabel ini setiap butir pertanyaan dan jawaban konsisten.

c. Disiplin kerja, nilai yang dihasilkan oleh variabel ini sebesar 0.777 dimana dengan ketentuan nilai lebih besar dari 0,6 sehingga hasil dari variabel disiplin kerja dalam pengujian yaitu reliabel. Dalam variabel ini setiap butir pertanyaan dan jawaban konsisten.

d. Prestasi kerja, nilai yang dihasilkan oleh variabel ini sebesar 0,751 dimana sesuai ketentuan nilai 0,751 lebih besar dari 0,6 sehingga hasil variabel prestasi kerja dalam pengujian yaitu reliabel. Dalam variabel ini setiap butir pertanyaan dan jawaban konsisten.

3. Hasil Analisis Regresi Linier Berganda

\begin{tabular}{|c|c|}
\hline \multirow{2}{*}{ Model } & $\begin{array}{c}\text { Unststandaridzized } \\
\text { coefisients }\end{array}$ \\
\cline { 2 - 2 } & $\mathrm{B}$ \\
\hline (Constant) & 1,140 \\
\hline Gaya kepemimpinan &, 186 \\
\hline Motivasi &, 128 \\
\hline Disiplin Kerja &, 356 \\
\hline \multicolumn{2}{|c|}{ Berdasarkan hasil olah data }
\end{tabular}

menggunakan SPSS 20 tersebut dapat diperoleh nilai konstanta sebesar 1,140, koefisien gaya kepemimpinan $\quad 0,186$, koefisien motivasi 0,128 , koefisien disiplin kerja 0,356, Maka persamaan regresi sebagai berikut :

$\mathrm{Y}=\alpha+\mathrm{b} 1 \mathrm{X} 1+\mathrm{b} 2 \mathrm{X} 2+\mathrm{b} 3 \mathrm{X} 3$

$\mathrm{Y}=1,140+0,186 \mathrm{x} 1+0,128 \mathrm{x} 2+$ $0,356 \times 3$ 
Persamaan regresi tersebut setiap nilai dapat diintepretasikan yaitu:

$\alpha=1,140$ merupakan nilai konstanta. Jika nilai dari X1, X2, dan X3 dimisalkan 0

maka nilai dari prestasi kerja akan meningkat sebesar 1,140.

a. Gaya kepemimpinan $(\beta 1)=0,186$. Koefisien bernilai positif artinya terjadi hubungan positif antara gaya kepemimpinan (X1) dan prestasi kerja karyawan semakin besar nilai gaya kepemimpinan (X1) semakin meningkat prestasi kerja. Koefisien gaya kepemimpinan 0,186 . Artinya jika variabel lain nilainya tetap dan variabel gaya kepemimpinan mengalami kenaikan 1 satuan maka prestasi kerja meningkat sebesar 0,186.

b. Motivasi $(\beta 2)=0,128$. Koefisien bernilai positif, terjadi hubungan positif antara motivasi (X2) dan prestasi kerja semakin besar motivasi semakin meningkat prestasi kerja. Koefisien regresi variabel motivasi sebesar 0,128. Artinya jika variabel lain nilainya tetap dan varaibel motivasi naik 1 satuan maka prestasi kerja meningkat 0,128 .

c. Disiplin Kerja $(\beta 3)=0,356$. Koefisien bernilai positif, terjadi hubungan positif antara disiplin kerja (X3) dan prestasi kerja, semakin besar disiplin kerja semakin meningkat prestasi kerja. Koefisien variabel disiplin kerja sebesar 0,356. Artinya variabel independen lainya tetap dan variabel disiplin kerjamengalami kenaikan 1 satuan maka prestasi kerja meningkat sebesar 0,356 .
4. Hasil Uji Parsial (Uji T)

\begin{tabular}{|l|c|c|}
\hline Variabel & $\mathrm{T}$ & Sig. \\
\hline Gaya kepemimpinan & 2,758 &, 007 \\
\hline Motivasi & 2,695 &, 008 \\
\hline Disiplin Kerja & 3,346 &, 001 \\
\hline \multicolumn{2}{|c|}{ Uji tilakukan } \\
\hline
\end{tabular}

membandingkan nilai t-hitung yang diperoleh pada tabel di atas, dengan taraf signifikansi 0,05 dan $\mathrm{df}=\mathrm{n}-\mathrm{k}=>$ $130-4=126$. Dengan ketentuan tersebut maka diperoleh t-tabel sebesar $=1,657$.

Pengujian hipotesis :

a. Gaya Kepemimpinan (X1)

Diketahui nilai Sig pada variable gaya kepemimpinan (X1) terhadap prestasi kerja (Y) sebesar $0,007<0,05$ dan nilai t-hitung sebesar 2,758>1,657 t-tabel, sehingga dapat disimpulkan $\mathrm{H} 1$ menerima Ha yang berarti bahwa terdapat pengaruh positif dan signifikan antara gaya kepemimpinan terhadap prestasi kerja.

b. Motivasi

Diketahui nilai Sig pada variable motivasi (X2) terhadap prestasi kerja (Y) sebesar 0,008 < 0,05 dan nilai t-hitung sebesar $2,659>1,657 \mathrm{t}$-tabel, sehingga dapat disimpulkan $\mathrm{H} 2$ menerima $\mathrm{Ha}$ yang berarti bahwa terdapat pengaruh positif dan signifikan antara motivasi terhadap prestasi kerja.

c. Disiplin Kerja

Diketahui nilai Sig pada variable disiplin kerja (X3) terhadap prestasi kerja (Y) sebesar $0,001<0,05$ dan nilai t-hitung sebesar 3,346>1,657 t-tabel, sehingga dapat disimpulkan $\mathrm{H} 3$ menerima Ha yang berarti bahwa terdapat pengaruh positif dan 
signifikan antara disiplin kerja terhadap prestasi kerja.

5. Hasil Uji Simultan (Uji F)

\begin{tabular}{|l|c|c|}
\hline Model & F & Sig \\
\hline Regression & 21,157 &, $000^{\mathrm{b}}$ \\
\hline
\end{tabular}

Dari uji ANOVA dengan menggunakan SPSS 20 bedasarkan tabel di atas, di dapat F-hitung sebesar 21,157. Bedasarkan tabel $\mathrm{F}$ taraf signifikansi $=5 \%$ diketahui $\mathrm{df} 1=\mathrm{k}-1=$ $4-1=3$ dan df $2=n-k=130-4=126$, maka F-tabel $=2,68$. Bedasarkan hasil perhitungan diperoleh hasil F-hitung = 21,157, sedangkan F-tabel $=2,68$. Hal ini menunjukan bahwa F-hitung 21,257 $>$ 2,68 F-tabel. Dengan demikian menunjukan bahwa H4 menerima $\mathrm{Ha}$, bahwa gaya kepemimpinan, motivasi dan displin kerja secara simultan berpengaruh positif dan signifikan terhadap prestasi kerja.

6. Hasil Uji Koefisien Determinasi

\begin{tabular}{|c|}
\hline R Square \\
\hline 0,335 \\
\hline
\end{tabular}

Dari hasil tersebut dapat diambil kesimpulan bahwa nilai $\mathrm{R}$ square sebesar 0,335 atau $33,5 \%$ mampu menjelaskan variabel prestasi kerja dipengaruhi variabel independen gaya kepemimpinan, motivasi dan disiplin kerja dan sisanya sebesar 66,5\% dipengaruhi oleh variabel lain yang tidak terdapat dipenelitian ini.

\section{Pembahasan}

Hasil hipotesis pertama yaitu gaya kepemimpinan berpengaruh positif secara signifikan terhadap prestasi kerja di kantor unit PT. TWC Prambanan dan Ratu Boko. Hal ini dibuktikan dengan adanya nilai signifikan sebesar 0,007 <
0,05. Hal tersebut menjelaskan bahwa gaya kepemimpinan yang baik dan tetap sebagai pimpinan akan mempengaruhi prestasi kerja pegawai PT. TWC Prambanan dan Ratu Boko. Seperti penelitian terdahulu yang dilakukan penelitian oleh Anggraini (2017) yang menyatakan bahwa gaya kepemimpinan berpengaruh positif terhadap prestasi kerja yang dilakukan pada kantor direktorat jendral perbendaharaan kota Kupang dimana penelitian itu menunjukan $\mathrm{Ha}$ diterima dan $\mathrm{HO}$ ditolak.

Penelitian tersebut membuktikan kebenaran teori Thoha (2010) gaya kepemimpinan merupakan norma perilaku yang digunakan oleh seseorang pada saat orang tersebut mencoba mempengaruhi perilaku orang lain seperti yang ia lihat. Peningkatan prestasi kerja dari sebuah perusahaan secara keseluruhan dibutuhkan suatu sistem manajemen dalam pengelolaan sumber daya yang ada, agar visi dan misi dari perusahaan tersebut dapat tercapai secara optimal. Evaluasi dan solusi secara terpadu diperlukan untuk menghadapi berbagai perma salahan, sehingga dapat tercapai prestasi kerja yang lebih baik, maka dilakukan suatu analisis tentang pengaruh gaya kepemimpinan, apabila gaya kepemimpinan tepat dan baik maka prestasi kerja akan meningkat sebaliknya apabila gaya kepemimpinan salah dan tidak tepat maka prestasi kerja menurun dan akan terjadi permasalahan terhadap karyawan dan menurunkan prestasi kerja karyawan.

Peryataan hipotesis kedua yaitu motivasi berpengaruh positif secara signifikan terhadap prestasi kerja di kantor unit PT. TWC Prambanan dan Ratu Boko. Hal ini dibuktikan dengan adanya nilai signifikan sebesar 0,008 < 0,05 . Hal tersebut menjelaskan bahwa motivasi yang dilakukan secara tepat dan 
terus menerus oleh pimpinan terhadap karyawan. Seperti penelitian terdahulu yang dilakukan penelitian oleh Dhinar (2014) menunjukkan bahwa motivasi kerja pegawai mempunyai pengaruh positif dengan prestasi kerja pegawai CV Triaji Kedunguter Banyumas. Dimana penelitian itu menujukan Ha diterima dan Ho ditolak yaitu dimana terdapat berpengaruh positif yang signifikan antara motivasi dan prestasi kerja.

Penelitian ini membuktikan kebenaran teori Menurut (Veithzal, 2010), Motivasi adalah serangkaian sikap dan nilai-nilai yang mempengaruhi individu untuk mencapai hal yang spesifik sesuai dengan tujuan individu. Sikap dan nilai nilai tersebut merupakan suatu yang invisibel yang memberikan kekuatan untuk mendorong individu bertingkah laku dalam mencapai tujuan. Ini menunjukkan bahwa motivasi kerja pegawai mempunyai pengaruh positif yang signifikan dengan prestasi kerja pegawai.

Peryataan hipotesis ketiga yaitu disiplin kerja berpengaruh positif secara signifikan terhadap prestasi kerja di kantor unit PT. TWC Prambanan dan Ratu Boko. Hal ini dibuktikan dengan adanya nilai signifikan sebesar $0,001<0,05$, sehingga dapat disimpulkan bahwa apabila para pegawai menerapkan kedisiplinan dan mematuhin aturan-aturan yang di tentukan oleh perusahaan maka akan meningkatkan prestasi kerja pegawai perusahaan tersebut dan variabel disiplin kerja ini sama hasilnya dengan penelitian yang peneliti lakukan pada sebelumya oleh Sariah (2017) menunjukkan bahwa disiplin kerja mempunyai pengaruh positif terhadap prestasi kerja pegawai PT. Multimas Nabati Ashan dimana hasil penelitian $\mathrm{Ha}$ diterima dan Ho ditolak.

Penelitian ini sejalan dengan teori Hasibuan (2012) disiplin kerja adalah kesadaran dan kesediaan seseorang menaati semua peraturan perusahaan dan norma-norma sosial yang berlaku. Kesadaran adalah sikap seseorang yang sec ara sukarela mentaati semua peraturan dan sadar akan tugas dan tanggung jawabnya. Jadi, dia akan mematuhi/ mengerjakan semua tugasnya dengan baik, bukan atas paksaan penerapan disiplin dapat membantu karyawan untuk bertindak lebih produktif yang pada masa mendatang akan menguntungkan dirinya dan perusahaan. Karyawan yang produktif dalam bekerja akan mengalami pengembangan karier atau prestasi kerja. Karyawan yang berprestasi adalah karyawan yang mematuhi dan melaksanakan segala tugas yang diberikannya dengan baik dan tepat waktu.

Peryataan hipotesis kempat yaitu variable gaya kepemimpinan, motivasi dan disiplin kerja secara bersama-sama berpengaruh positif terhadap prestasi kerja yang dibuktikan dengan F-hitung $21,157>2,68$ F-tabel. Hal tersebut membuktikan bahwa gaya kepemimpinan, motivasi dan disiplin kerja mempengaruhi prestasi kerja pegawai kantor unit PT. TWC Prambanan dan Ratu Boko. Hal tersebut didukung oleh bedasarkan beberapa penelitian terdahulu yang dilakukan Anggraini (2017) menunjukan bahwa gaya kepemimpinan dan motivasi kerja berpengaruh positif terhadap prestasi kerja dan penelitian yang dilakukan oleh Sariah (2017) menunjukan bahwa disiplin kerja berpengaruh positif terhadap prestasi kerja.

\section{KESIMPULAN DAN SARAN}

\section{Kesimpulan}

1. Karakteristik responden di dominasi karyawan berjenis kelamin laki-laki yaitu sebanyak $112(86,2 \%)$, usia yang mendominasi adalah diatas 40 tahun sebanyak 110 (84,7\%), pendidikan 
terakhir yang mendominasi adalah SMA/ SMK sebanyak 112 (86,2\%) dan semua telah bekerja selama $>6$ tahun.

2. Hasil Uji Validitas dan Reliabilitas

Berdasarakan tabel uji validitas yang dijelaskan pada bab sebelumnya dari tabel hasil proses menggunakan software SPSS 20 terlihat bahwa nilai factor loading dari setiap butir pertanyaan yang mewakili variable gaya kepemimpinan, motivasi, disiplin kerja dan prestasi kerja > 0,50. Maka dapat disimpulkan diperoleh 22 item pertanyaaan dari 42 pertanyaan yang mewakili variable gaya kepemimpinan, motivasi, disiplin kerja dan prestasi kerja adalah butir pertanyaan yang valid.Dan pada uji reliabilitas, dapat dilihat juga bahwa hasil dari proses pengolahan data menggunakan software SPSS 20 butir pertanyaan yang mewakili variabel gaya kepemimpianan, motivasi, disiplin kerja dan prestasi kerja nilai cronbach's alpha berada diatas 0,70. Maka dapat disimpulkan bahwa butir-butir instrumen penelitian tersebut reliabel.

\section{Uji Analisis Linier Berganda}

Berdasarkan hasil olah data menggunakan software SPSS 20 tersebut dapat diperoleh nilai konstanta sebesar 1,140, koefisien gaya kepemimpinan 0,186 , koefisien motivasi 0,128, koefisien disiplin kerja 0,356, Maka persamaan regresi sebagai berikut :

$\mathrm{Y}=1,140+0,186 \mathrm{x} 1+0,128 \mathrm{x} 2+$ $0,356 \times 3$

Persamaan regresi tersebut setiap nilai dapat diintepretasikan yaitu:

$\mathrm{a}=1,140$ merupakan nilai konstanta. Jika nilai dari $\mathrm{X} 1, \mathrm{X} 2$, dan $\mathrm{X} 3$ dimisalkan 0 maka nilai dari prestasi kerja akan meningkat sebesar 1,140.

a. Gaya kepemimpinan $(\beta 1)=0,186$. Koefisien bernilai positif artinya terjadi hubungan positif antara gaya kepemimpinan (X1) dan prestasi kerja karyawan semakin besar nilai gaya kepemimpinan (X1) semakin meningkat prestasi kerja. Koefisien gaya kepemimpinan 0,186. Artinya jika variabel lain nilainya tetap dan variabel gaya kepemimpinan mengalami kenaikan 1 satuan maka prestasi kerja meningkat sebesar 0,186 .

b. Motivasi $(\beta 2)=0,128$. Koefisien bernilai positif, terjadi hubungan positif antara motivasi (X2) dan prestasi kerja semakin besar motivasi semakin meningkat prestasi kerja. Koefisien regresi variabel motivasi sebesar 0,128. Artinya jika variabel lain nilainya tetap dan varaibel motivasi naik 1 satuan maka prestasi kerja meningkat 0,128 .

c. Disiplin Kerja $(\beta 3)=0,356$. Koefisien bernilai positif, terjadi hubungan positif antara disiplin kerja (X3) dan prestasi kerja, semakin besar disiplin kerja semakin meningkat prestasi kerja. Koefisien variabel disiplin kerja sebesar 0,356. Artinya variabel independen lainya tetap dan variabel disiplin kerja mengalami kenaikan 1 satuan maka prestasi kerja meningkat sebesar 0,356 .

\section{Hasil Uji Parsial (Uji T)}

a. Gaya Kepemimpinan (X1)

Diketahui nilai Sig pada variable gaya kepemimpinan (X1) terhadap prestasi kerja (Y) sebesar 0,007 < 0,05 dan nilai t-hitung sebesar 2,758 
$>$ 1,657 t-tabel. Sehingga dapat disimpulkan H1 menerima Ha yang berarti bahwa terdapat pengaruh positif dan signifikan antara gaya kepemimpinan terhadap prestasi kerja pegawai PT Taman Wisata Candi Borobudur, Prambanan \& Ratu Boko..

b. Motivasi

Diketahui nilai Sig pada variable motivasi (X2) terhadap prestasi kerja (Y) sebesar 0,008 <0,05 dan nilai t-hitung sebesar 2,695>1,657 t-tabel. Sehingga dapat disimpulkan $\mathrm{H} 2$ menerima $\mathrm{Ha}$ yang berarti bahwa terdapat pengaruh positif dan signifikan antara motivasi terhadap prestasi kerja pegawai PT Taman Wisata Candi Borobudur, Prambanan \& Ratu Boko.

c. Disiplin Kerja

Diketahui nilai Sig pada variable disiplin kerja (X3) terhadap prestasi kerja (Y) sebesar 0,001 < 0,05 dan nilai t-hitung sebesar 3,346 $>$ 1,657 ttabel. Sehingga dapat disimpulkan $\mathrm{H} 3$ menerima Ha yang berarti bahwa terdapat pengaruh positif dan signifikan antara disiplin kerja terhadap prestasi kerja pegawai PT Taman Wisata Candi Borobudur, Prambanan \& Ratu Boko.

\section{Hasil Uji Simultan (Uji F)}

Bedasarkan hasil perhitungan yang dilakaukan menggunakan softwareSPSS 20 diperoleh hasil Fhitung $=21,157$ sedangkan F-tabel $=$ 2,68. Hal ini menunjukan bahwa Fhitung 21,157 > 2,68 F-tabel, dengan demikian menunjukan bahwa $\mathrm{H} 4$ menerima $\mathrm{Ha}$, bahwa gaya kepemimpinan, motivasi dan displin kerja secara simultan berpengaruh positif dan signifikan terhadap prestasi kerja pegawai PT Taman Wisata Candi Borobudur, Prambanan \& Ratu Boko.

\section{Hasil Koefisien Determinasi (R2)}

Dari hasil perhitungan olah data menggunakan software SPSS 20 diambil kesimpulan bahwa nilai R2 sebesar 0,335 atau 33,5\% mampu menjelaskan variabel prestasi kerja dipengaruhi variabel independen gaya kepemimpinan, motivasi dan disiplin kerja dan sisanya sebesar 66,5\% dipengaruhi oleh variabel lain yang tidak terdapat dipenelitian ini.

\section{Saran}

1. Bagi Perusahan PT Taman Wisata Candi Borobudur, Prambanan \& Ratu Boko ( Persero ).

Gaya kepemimpinan yang sesuai dengan keinginan instansi pemerintahan adalah perlu adanya pengarahan kepada pegawai atau bawahan, serta membantu mereka agar bisa mengatasi kesulitankesulitan dan memudahkan mereka dalam menjalankan tugas-tugas sesuai dengan yang telah di tentukan dan juga disiplin kerja harus dibuat sebaik mungkin demi terciptanya rasa tanggung jawab akan sebuah pekerjaan dan dapat meciptakan suasana kantor yang nyaman serta kondusif. Dengan adanya penelitian ini diharapkan PT Taman Wisata Candi Borobudur, Pramabanan \& Ratu Boko manfaatkan penelitian ini sebagai bahan pertimbangan agar lebih memperhatikan kebutuhan pegawai terlebih pada gaya kepempimpian dan motivasi yang diberikan serta disiplin kerja yang diterapkan untuk meningkatkan prestasi pegawai yang lebih baik. 
2. Bagi Akademisi

Bagi kalangan akademisi, penelitian ini diharapkan dapat menjadi referensi untuk penelitianpenelitian selanjutnya yang memiliki tema yang sama yaitu pengaruh gaya kepemimpinan, motivasi dan disiplin kerja terhadap prestasi kerja pegawai. Penelitian selanjutnya disarankan untuk mengkaji komponen lain selain masalah gaya kepemimpinan, motivasi, disiplin kerja dan kinerja pegawai yang telah dibahas oleh penulis atau dengan dimensi dan indikator yang berbeda sehingga pengetahuan akan ilmu manajemen sumber daya manusia untuk masyarakat akan semakinberkembang dan berguna untuk masa yang akan datang. Penelitian yang selanjutnya juga disarankan untuk mencari ruang lingkup yang lebih luas dari populasi dalam penelitian ini. Sehingga sampel yang digunakan dapat lebih banyak, sehingga dapat memberikan gambaran yang lebih spesifik mengenai gaya kepemimpinan, motivasi dan disiplin kerja terhadap prestasi kerjapegawai.

\section{DAFTAR PUSTAKA}

Anggraini, Yunita Madi dan Darti Djuharni. (2017). Pengaruh Gaya Kepemimpinan dan Motivasi Terhadap Prestasi Kerja Pegawai Kantor Direktorat Jendral Perbendaharaan Kota Kupang. Jurnal Administrasi dan Bisnis. Vol. 11.

Ardana, I Komang, Ni Wayan Mujiati dan I Wayan Mudiartha Utama. (2011). Manajemen Sumber Daya Manusia. Edisi Pertama : Graha Ilmu.
Bangun, Wilson. (2012). Manajemen Sumber Daya Manusia. Bandung: Erlangga.

Brahmasari, Ida Ayu dan Agus Suprayetno. (2008). Motivasi Kerja Berpengaruh Positif dan Signifikan Terhadap Kepuasan Kerja Karyawan. Jurnal Manajemen dan Kewirausahaan. 10(2): h: 124-135.

Dhinar, Apsari. (2014). Pengaruh Motivasi Kerja Terhadap Prestasi Kerja Karyawan CV. Triaji Kedunguter Banyumas. Skripsi. Purwokerto: Sekolah Tinggi Agama Islam Negri Purwokerto.

Ghozali, Imam . (2011). Aplikasi Analisis Multivariate dengan Program IBM SPSS 19. Semarang: Badan Penerbit Universitas Diponegoro.

Hair, J.F., Black, W.J., Babin, B.J., \& Anderson, R.E. (2010). Multivariate data analysis. Englewood Cliff, NJ: Prentice Hall.

Handoko, T. Hani. (2008). Manajemen. Yogyakarta: BPFE.

Hasibuan, S.P Melayu. (2012). Manajemen Sumber Daya Manusia. Edisi Ketiga. Jakarta: Bumi Aksara.

Iriani, Nur Ida. (2010). Motivasi Intrinsik, Motivasi Ekstrinsik, dan Disiplin Kerja Pengaruhnya Terhadap Kinerja Pegawai pada Kantor Dinas Pendidikan Kabupaten Sambas. Jurnal Aplikasi Manajemen. 8(2): h: 561-569.

Latan, H. (2012). Structural Equation Modeling Konsep dan Aplikasi Menggunakan LISREL $8,80$. Bandung: Alfabeta.

Mangkunegara, Anwar Prabu. (2010). Manajemen Sumber Daya Manusia. Bandung: Rosdakarya.

Sariah, Azar. (2017). Pengaruh Disiplin Kerja Terhadap Prestasi Kerja 
Karyawan PT. Multimas Nabati Ashan. Skripsi. Medan: Universitas Negri Islam Sumatra Utara.

Sastrohadiwiryo, B Siswanto. (2002). Manajemen Tenaga Kerja Indonesia Pendekatan Administrasi Dan Oprasional. Jakarta: Bumi Aksara.

Sugiyono. (2010). Statistika Untuk Penelitian. Bandung: Alfabeta.

Sutrisno, Edi. (2007). Manajemen Sumber Daya Manusia. Edisi Pertama. Jakarta: Kencana Prenda Media Group.

Thoha, Miftah. (2010). Kepemimpinan dalam Manajemen. Jakarta : Raja Grafindo Persada.

Veithzal, Rivai dan Ella Jauvani Sagala. (2010). Manajemen Sumber Daya Manusia untuk Perusahaan. Cetakan ke 3. Jakarta: Rajawali Pers. 